\title{
3 Research Square

\section{Individualized transscleral cyclophotocoagulation as the initial surgical intervention for medically uncontrolled glaucoma after blunt trauma}

Xu Hou ( $\nabla$ hxfmmu@163.com )

Eye Institute of Chinese PLA https://orcid.org/0000-0002-2781-7219

Jing Wu

Eye Institute of Chinese PLA

Jian Zhou

Eye Institute of Chinese PLA

Yu-Sheng Wang

Eye Institute of Chinese PLA

Dan Hu

Eye Institute of Chinese PLA

Research article

Keywords: Transscleral cyclophotocoagulation, Glaucoma, Blunt trauma, Diode laser

Posted Date: August 26th, 2020

DOl: https://doi.org/10.21203/rs.3.rs-63002/v1

License: (9) This work is licensed under a Creative Commons Attribution 4.0 International License. Read Full License

Version of Record: A version of this preprint was published at European Journal of Ophthalmology on October 23rd, 2020. See the published version at https://doi.org/10.1177/1120672120965512. 


\section{Abstract}

Background: To investigate the safety and feasibility of individualized transscleral cyclophotocoagulation (TSCPC) as the initial non-incisional surgical intervention for medically uncontrolled glaucoma after blunt trauma.

Methods: The therapy records were reviewed of medically uncontrolled traumatic glaucoma after blunt trauma treated with TSCPC in a single hospital between January 2014 and December 2018. 31 patients (31 eyes) received individualized TSCPC after ultrasound biomicroscopy and gonioscopy examination to localize and quantify the injured quadrants of the anterior chamber angle. In addition to the number of IOP lowing drugs, visual acuity (VA), IOP, inflammation and hemorrhage in the anterior chamber were analyzed at 1 day, 3 weeks and 3 months after operation, respectively. Success was defined as the IOP was not more than $21 \mathrm{mmHg}$.

Results: Compared with the data of pre-operation, constituent ratio of VA had no significant difference at 3 weeks $\left(c^{2}=0.56, P>0.75\right)$. At 3 months the mean IOP was $22.2 \pm 5.0 \mathrm{mmHg}$, which was significantly lower than that of pre-operation $(46.6 \pm 5.6 \mathrm{mmHg})(\mathrm{t}=19.818, P<0.001)$. No IOP lowing drug was needed in 12 eyes, and more than 3 kinds of drugs were still needed in 5 eyes. The average number of medications decreased significantly $\left(c^{2}=93.496 \otimes P \otimes 0.001\right)$. The complete success rate was $38.7 \%$ and the relative success rate (combined with no more than two kinds of drugs) was $83.9 \%$ at 3 months.

Conclusions: Individualized TSCPC could be applied as an initial non-incisional surgical intervention to treat traumatic glaucoma refractory to the medicine therapy.

\section{Background}

The patients of ocular trauma in China were estimated to be about 5 million to 12 million per year ${ }^{1}$. Closed globe injury accounted for about one third of patients hospitalized for ocular trauma ${ }^{2-3}$. Ocular contusion was the main type of closed globe injury, which was often accompanied by high intraocular pressure (IOP). If IOP could not be controlled quickly and effectively, optic atrophy would lead to blindness. Traumatic angle recession, inflammation, intraocular hemorrhage and lens-related factors were the most important pathogenesis of secondary glaucoma after blunt trauma ${ }^{4-5}$. Topical and systemic IOP lowering drugs were the common initial medical treatment. Targeting at the main factors leading to elevated IOP, timely operation to remove severe intraocular hemorrhage, lens subluxation and vitreous hernia was suitable strategy ${ }^{6}$. If these surgical indications were not available, close clinical observation and selective surgical repair of the intraocular injury when the condition was stable could be a reasonable choice. However, the IOP of some cases might be beyond control of the maximum tolerated medications. Early anti-glaucoma surgery would be inevitable.

Routine surgical intervention for medically uncontrolled glaucoma was trabeculectomy or tube implantation. Cyclophotocoagulation was often performed only as the secondary or even the last option. 
However, successful outcomes of refractive glaucoma treated by transscleral cyclophotocoagulation (TSCPC) had ever been reported ${ }^{7-9}$. In the study individualized TSCPC was applied as the primary nonincisional surgery based on careful evaluation of the severity of anterior chamber angle injury and elevated IOP by ultrasound biomicroscopy (UBM) and gonioscopy examination, the safety and feasibility of the operation were evaluated for 3 months.

\section{Methods}

\section{Patients}

Retrospective analysis was performed on the medical documents of the traumatic glaucoma patients after ocular contusion treated with individualized TSCPC in our hospital from January 2014 to December 2018. The recruited patients signed informed consent before operation and the study was approved by the ethical and academic board of Xijing hospital. All procedures used conformed to the tenets of the Declaration of Helsinki. Diagnostic criteria of traumatic glaucoma after ocular contusion: pathological elevation of IOP because of closed globe injury, which would lead to glaucomatous optic neuropathy and need to be controlled with anti-glaucoma medications or operation. The inclusion and exclusion criteria for patients in the study was as following.

Inclusion criteria:

1. Male or female over 18 years old;

2. Closed globe injury with no corneal or scleral wound according to the terminology and classification of mechanical eye injuries of the International Society of Ocular Trauma;

3. The presence of anterior angle recession, iris or ciliary body injury, with or without anterior chamber and vitreous hemorrhage;

4. After 7 to 14 days of topical and systemic maximum tolerated medicine therapy, the IOP was still higher than $35 \mathrm{mmHg}$, visual acuity $<0.3$.

Exclusion criteria:

1. Patients requiring early surgical intervention because of the following condition: total hyphema, severe lens displacement or rupture, dense vitreous hemorrhage, retinal or choriodal detachment;

2. Combined with life-threatening trauma such as craniocerebral, maxillofacial or systemic injuries requiring emergency treatment;

3. Ocular surgery or trauma history before this time;

4. Prior diagnosis of high IOP or glaucoma, history of treatment with laser or anti-glaucoma medications;

5. Undiagnosed and untreated glaucoma before ocular trauma;

6. Ocular diseases such as uveitis, hypermature cataract, retinal vascular disease; 
7. Chronic drug use of steroid or antidepressants;

8. Uncontrolled hypertension or diabetes

\section{Surgical technique}

Information including gender, age, occupation, injury date and source, tissues involved, best corrected vision acuity (BCVA) and IOP were filled according to the forms of World Eye Injury Registry.

After localization and quantification of the injured quadrants of the globe by UBM and gonioscopy examination, $2 \sim 3$ quadrants covered the injured angle were selected to perform TSCPC with diode laser (Iridex Corporation, Mountain View, CA, USA) under retrobulbar anaesthesia with ropivacaine $1 \%$ and lidocaine $2 \% \operatorname{mix}(1: 3)$. During laser delivery, the probe was placed $1.5 \mathrm{~mm}$ posterior to the corneal limbus avoiding the 3 and 9 o'clock positions. The initial laser energy setting was $2000 \mathrm{~mW}$ and the treatment duration was $2000 \mathrm{~ms}$. If the 'pop' sound was inaudible, the energy setting was increased by $250 \mathrm{~mW}$ and the maximum power of the diode laser did not exceed $3000 \mathrm{~mW}$. $25 \sim 40$ burns were distributed evenly at the discretion of the clinician depending on the level of IOP (if IOP $>40 \mathrm{mmHg}, 35 \sim$ 40 burns) followed by subconjunctival injection of dexamethasone $0.2 \mathrm{mg}$. Topical bromofenac sodium and prednisolone acetate eye drops were applied for $4 \sim 6$ weeks after operation.

The BCVA, IOP, inflammation and haemorrhage in the anterior chamber, glaucoma medications were observed after operation at 1 day, 3 weeks and 3 months. The complete success was defined as: The IOP was less than $22 \mathrm{mmHg}$ without glaucoma medications. The relative success was defined as: The IOP was less than $22 \mathrm{mmHg}$ combined with no more than two anti-glaucoma medications. The order of combined medication was beta-blockers, alpha agonists, carbonic anhydrase inhibitors, and prostaglandin analogues. Patients needing vitreous or cataract surgery due to injury progression during the follow-up were removed.

\section{Statistical analysis}

Data analysis was performed with SPSS software, version 19.0 (SPSS Inc, Chicago, IL, USA). Continuous variables were presented as mean \pm standard deviation. Classified data were presented as the number ( $n$ ) and percentage (\%). The paired T-test was used for comparison of the level of IOP between pre-operation and post-operation at different time points. Both the constituent ratio of BCVA and the average number of medications before and after operation were analyzed by the chi-square test. Statistical significance was considered at $P<0.05$.

\section{Results}

\section{Baseline Characteristics}

A total of 31 patients (31 eyes) were included. There were 28 males $(90.3 \%)$ and 3 females $(9.7 \%)$. The average age was $36.6 \pm 11.9$ years ( $19 \sim 66$ years). Age groups were recommended by the Chinese Society of Ocular Trauma: 4 cases were $18 \sim 24$ years old (12.9\%), 25 cases were $25 \sim 55$ years old $(80.6 \%), 2$ cases were over 55 years $(6.5 \%)$. The young and middle-aged were the main population of 
ocular contusion. Injury source and place included fist, fireworks, motor vehicle crash, recreation \& sport, industrial premises and home (Table 1). The main ocular injuries of these patients included hemorrhage in the anterior chamber and vitreous, anterior angle recession, iridodialysis, lens subluxation. 27 patients were treated with TSCPC in 3 quadrants of the globe. 4 patients were treated on 2 quadrants since the accumulated injured angle was not more than $180^{\circ}$. The injuried quadrants confirmed by UBM and gonioscopy examination was selected as the location for treatment.

Table 1

The distribution of the injury source and place in different age groups

\begin{tabular}{|c|c|c|c|c|c|c|c|}
\hline \multirow{2}{*}{$\begin{array}{l}\text { Age } \\
\text { (years) }\end{array}$} & \multirow{2}{*}{$\begin{array}{l}\text { Cases } \\
\text { (n) }\end{array}$} & \multicolumn{6}{|c|}{ Source and place (ম: female) } \\
\hline & & Fist & Fireworks & $\begin{array}{l}\text { Industrial } \\
\text { premises }\end{array}$ & $\begin{array}{l}\text { Recreation } \\
\text { \& sport }\end{array}$ & $\begin{array}{l}\text { Motor vehicle } \\
\text { crash }\end{array}$ & Home \\
\hline $18 \sim 24$ & 4 & 1 & & & $3(1 \rrbracket)$ & & \\
\hline $25 \sim 55$ & 25 & $\begin{array}{l}8 \\
\text { (1区) }\end{array}$ & 3 & 2 & $7(1 \rrbracket)$ & 4 & 1 \\
\hline Over 55 & 2 & & & & & 1 & 1 \\
\hline Total & 31 & $\begin{array}{l}9 \\
(1 区)\end{array}$ & 3 & 2 & $10(2 \rrbracket)$ & 5 & 2 \\
\hline
\end{tabular}

\section{Best corrected visual acuity (BCVA)}

The BCVA was graded according to the International Society of Ocular Trauma as NLP, LP/HM, 0.005$0.095,0.1-0.3$. The constituent ratio of BCVA after injury and 3 weeks after treatment was shown in Fig. 1. There was no significant difference in constituent ratio of BCVA by chi-square test $\left(\chi^{2}=0.56\right.$, $P \otimes 0.75)$.

\section{IOP and the success rate}

The IOP was significantly reduced on the first day after surgery. At 3 weeks, the IOP of 17 patients were normal without medications. At 3 months, the IOP of 12 patients were normal without medications, at least 3 kinds of drugs were needed in 5 cases. Paired T-test showed that the IOP was significantly lower at all time points after the operation than that before operation $(P \otimes 0.001)$. The average number of medications was reduced obviously after operation by the chi-square test $\left(\chi^{2}=93.496, P \otimes 0.001\right)$. The complete success rate was $38.7 \%$ and the relative success rate (combined with no more than two kinds of drugs) was $83.9 \%$ at 3 months (Table 2). One patient received the second TSCPC after 3 months because of higher IOP. 
Table 2

IOP and anti-glaucoma medications before and after operation

\begin{tabular}{|c|c|c|c|c|c|c|c|c|}
\hline \multirow[t]{2}{*}{ Time } & \multirow{2}{*}{$\begin{array}{l}\text { IOP }(\mathrm{mmHg}) \\
(95 \% \mathrm{Cl})\end{array}$} & \multirow[t]{2}{*}{$\mathrm{t}$} & \multirow{2}{*}{$\begin{array}{l}P \\
(\mathbb{X})\end{array}$} & \multicolumn{3}{|c|}{ Medications (eye) } & \multicolumn{2}{|c|}{ Success rate(\%) } \\
\hline & & & & None & $\frac{5}{2}$ & $\frac{2}{3}$ & complete & relative \\
\hline $\begin{array}{l}\text { Pre- } \\
\text { operation }\end{array}$ & $\begin{array}{l}46.6 \pm 5.6(44.6- \\
48.7)\end{array}$ & & & 0 & 0 & 31 & & \\
\hline 1 day & $\begin{array}{l}23.6 \pm 6.1(21.4- \\
25.8)\end{array}$ & 17.011 & 0.001 & 16 & 15 & 0 & 51.6 & 100 \\
\hline 3 weeks & $\begin{array}{l}22.5 \pm 5.0(20.7- \\
24.4)\end{array}$ & 18.911 & 0.001 & 17 & 11 & 3 & 54.8 & 90.3 \\
\hline 3 months & $\begin{array}{l}22.2 \pm 5.0(20.3- \\
24.0)\end{array}$ & 19.818 & 0.001 & 12 & 14 & 5 & 38.7 & 83.9 \\
\hline
\end{tabular}

Complications

On the first day after operation mild to moderate bulbar conjunctival hyperemia and chemosis occurred. A small amount of dusty and pigmented keratic precipitates could be seen on the posterior surface of the cornea. Moderate flare and inflammatory cells were present in the anterior chamber, and hemorrhagic aqueous humor could be seen in some cases. However, there was no massive hyphema increased in the anterior chamber compared with that before operation. At 3 weeks, chemosis disappeared with or without mild congestion, and there were few inflammatory cells in the anterior chamber. The IOP of 2 patients were lower than $7 \mathrm{mmHg}$ after surgery and recovered within a week after treatment. During the 3 months of follow-up the patients showed no persistent hypotony or eyeball atrophy.

\section{Discussion}

Intraocular inflammation and haemorrhage, trabecular meshwork edema, Schlemm's canal collapse, anterior chamber angle closure or recession, lens displacement and vitreous hernia after blunt trauma could lead to obstruction of aqueous humor drainage and secondary glaucoma. The massive haemorrhage in the anterior chamber and vitreous, the severe lens displacement and vitreous hernia should be removed actively in case of IOP elevation. However, the trabecular meshwork injury might block aqueous humor drainage with an uncertain outcome of IOP, surgical intervention should be considered until the medications did not work effectively. With the maximum tolerated medicine therapy, how long should we follow before operation if the IOP was out of control? What surgical option should we choose? This study hoped to offer some reasonable suggestions.

Pathological high IOP could cause irreversible glaucomatous optic neuropathy and lower peripapillary retinal vessel density. Even after acute primary angle closure (APAC) the retinal nerve fiber layer and 
ganglion cell complex gradually decreased up to 12 months ${ }^{10-11}$. The guideline of the treatment of APAC had been interpreted clearly nowadays. However, the pathogenesis of secondary glaucoma after contusion was complex and the injury characteristics were different from case to case, so it was difficult to use a unified standard to formulate the treatment plan. The damage degree of trabecular meshwork and Schlemm's canal had a great impact on the outcome of IOP after ocular contusion. The more serious the injury was, the earlier the glaucoma occurred and the more difficult it was to control ${ }^{5}$. The amplitude and duration of elevated IOP were positively correlated with apoptosis of retinal ganglion cells ${ }^{12}$. Antiinflammatory and hemostasis treatment was helpful to control IOP. Topical and systemic use of IOP lowering drugs could reduce the secondary injury of the optic nerve. Operation would be more conducive to the maintenance of visual function as long as the level of IOP was not safe enough for the patients after medicine therapy. In the study, TSCPC was performed because of persistent uncontrolled IOP after 7 to 14 days of medicine treatment.

When dealing with uncontrolled IOP induced by trauma, higher risk and incidence of complications often made both ophthalmologists and patients uneasy to make the decision for surgery. Incisional surgical intervention like trabeculectomy and drainage implantation was a kind of option. Ahmed or Baerveldt tube shunt provided successful control of IOP in patients with medically uncontrollable traumatic glaucoma in several small sample observations. However, hypotony, shallow anterior chamber, hyphema, tube extrusion might fail the surgery ${ }^{13-14}$. In addition, complications of incisional surgery in the early stage might include: moderate to severe inflammation, intraocular hemorrhage, IOP fluctuation followed by aggravation of lens displacement and vitreous hernia, earlier scarring and vascularization of filtering bleb. Traumatic glaucoma was often complicated with other intraocular injuries, which could increase the complexity of treatment. So when choosing incisional surgery, the issues like incision position, bleb location, combined surgery or not, and the surgical impact on the future treatment should all be taken into account. For instance, the inferotemporal quadrant should be selected as the best operative approach when the drainage valve was inserted for the glaucoma patients who would need vitrectomy combined with silicone oil filling in the later stage ${ }^{15}$.

As an non-incisional surgical intervention, TSCPC had been applied to treat acute angle closure refractory to medical treatment safely and effectively ${ }^{16-17}$. Additionally, a study of secondary glaucoma in children after ocular trauma and cataract surgery found that TSCPC had a similar effect on controlling IOP and maintaining visual function as trabeculectomy. Meanwhile, the incidence of complications of TSCPC was lower, while the success rate of trabeculectomy depended more on the convenience of follow-up and postoperative care ${ }^{18}$. Another study showed a substantial and long-term reduction of IOP in glaucoma patients following TSCPC ${ }^{19}$. Glaucoma patients with good VA could also be treated with TSCPC safely and effectively in controlling IOP. The loss of VA in some patients was similar to the patients having trabeculectomy or tube surgery ${ }^{20-21}$.

TSCPC had its own advantages, including a simpler procedure, less postoperative care and follow-up, lower cost and notable effect. So it was suitable for the patients who might not qualify for 
trabeculectomy or tube implantation. In our study individualized TSCPC was applied as the initial nonincisional surgical intervention for traumatic glaucoma patients with potential visual function. The injured quadrants of the anterior chamber angle was confirmed by UBM and gonioscopy examination before personalized treatment parameter was set. The relative success rate (combined with no more than two kinds of drugs) was $83.9 \%$ at 3 months which was comparable as the previous study. The BCVA was stable at 3 weeks. The data of BCVA at 3 months were not analyzed because the complicated factors related to trauma itself might result in cataract development or atrophy of the optic nerve leading to vision loss. After 3 months, some patients underwent cataract extraction, vitrectomy or intravitreal injection due to the progression of traumatic cataract, macular hole or choroidal neovascularization. So the data quality and consistency were not good for analysis then. The most common complication was postoperative iritic. Hyphema was rare, and a little bleeding or hemorrhagic aqueous humor could be absorbed within 1 week generally. The IOP of 2 patients were lower than $7 \mathrm{mmHg}$ related to the low secretion of the shocked ciliary body and both recovered with the treatment of anti-inflammation and paralysis of the ciliary muscle.

Over the past several decades, cyclodestructive techniques like cyclodiathermy and cyclocryotherapy had been reserved as the final options for refractory glaucoma because of the complications including pain, hyphema, vision loss, hypotony and phthisis ${ }^{22}$. With the development of technology, innovations of micropulse transscleral cyclophotocoagulation and high-intensity focused ultrasound was available in clinic. Lower damage, minimal invasion and fewer complications made the interpretive term "destructive" out of date and improper. New encouraging clinical results cast a broad view in the application of this kind of surgery as primary treatment for refractory glaucoma ${ }^{23-25}$.

\section{Conclusions}

In this study TSCPC treatment created conditions and foundations for other ocular trauma-related complications that might need to be dealt with and visual function rehabilitation at a later stage. This single center retrospective study might bias because of the relatively small sample and the inconsistency of medication schemes. In order to evaluate clinical therapeutic value of TSCPC for these patients, we advocated to carry out a multi-center study on the treatment of medically uncontrolled glaucoma after blunt trauma with individualized TSCPC as a preferred procedure in the future. And also, it would be very meaningful to investigate whether the outcome of the BCVA could be improved if the time point of the operation was a few more days in advance.

\section{Abbreviations}

TSCPC: transscleral cyclophotocoagulation; VA: visual acuity; IOP: intraocular pressure; UBM: ultrasound biomicroscopy; BCVA: best corrected vision acuity; NLP: no light perception; LP: light perception; HM: hand move; APAC: acute primary angle closure

\section{Declarations}


Acknowledgements

The authors acknowledge Dr. Zhe Yang for her statistical support.

\section{Author's contributions}

$\mathrm{XH}$ and $\mathrm{DH}$ designed the study. XH performed all surgeries. $\mathrm{XH}$ and JW collected and analyzed all data. $\mathrm{XH}, \mathrm{JW}$ and $\mathrm{DH}$ interpreted the data and results. XH drafted the manuscript. JZ and YW reviewed the manuscript. All authors read and approved the final manuscript.

\section{Author's information}

Null.

\section{Funding}

The study was supported by the National Nature Science Foundation of China (Grant No. 81371034) and the Key Project of the Natural Science Foundation of Shaanxi Province (Grant No. 2017JZ025). The funding organization had no role in the design or conduct of this research.

\section{Availability of data and materials}

The datasets used and/or analysed during the current study are available from the corresponding author on reasonable request.

\section{Ethics approval and consent to participate}

The study was in compliance with the tenets of the Declaration of Helsinki. The Ethics Cmmittee of Xijing Hospital approved the study protocol. All participants gave written informed consent.

\section{Consent for publication}

Not applicable

\section{Competing interests}

The authors declare that they have no competing interests.

\section{References}

1. Yan $\mathrm{H}$. [The challenge and present condition of management of ocular trauma in China]. Zhonghua Yan Ke Za Zhi 2015; 51: 561-564. 2015/12/24.

2. Cao H, Li L and Zhang M. Epidemiology of patients hospitalized for ocular trauma in the Chaoshan region of China, 2001-2010. PLoS One 2012; 7: e48377. 2012/11/03. DOI: 
PONE-D-12-10104 [pii].

3. Wang W, Zhou Y, Zeng J, et al. Epidemiology and clinical characteristics of patients hospitalized for ocular trauma in South-Central China. Acta Ophthalmol 2017; 95: e503-e510. 2017/04/04. DOI: $10.1111 /$ aos.13438.

4. Schlote T and Rohrbach M. [Traumatic glaucoma-a survey]. Klin Monbl Augenheilkd 2005; 222: 772-782. 2005/10/22. DOI: 10.1055/s-2005-858458.

5. Ozer PA, Yalvac IS, Satana B, et al. Incidence and risk factors in secondary glaucomas after blunt and penetrating ocular trauma. J Glaucoma 2007; 16: 685-690. 2007/12/20. DOI:

10.1097/IJG.0b013e318073bd4d 00061198-200712000-00008 [pii].

6. Bai HQ, Yao L, Wang DB, et al. Causes and treatments of traumatic secondary glaucoma. Eur J Ophthalmol2009; 19: 201-206. 2009/03/03.

7. Yusuf IH, Shah M, Shaikh A, et al. Transscleral cyclophotocoagulation in refractory acute and chronic angle closure glaucoma. BMJ Case Rep 2015; 2015 2015/10/02. DOI: bcr-2015-209552 [pii] 10.1136/bcr-2015-209552.

8. Bendel RE and Patterson MT. Observational report: Improved outcomes of transscleral cyclophotocoagulation for glaucoma patients. Medicine (Baltimore) 2017; 96: e6946. 2017/06/08. DOI: 10.1097/MD.0000000000006946 00005792-201706090-00005 [pii].

9. Cheung JJC, Li KKW and Tang SWK. Retrospective review on the outcome and safety of transscleral diode laser cyclophotocoagulation in refractory glaucoma in Chinese patients. Int Ophthalmol2019; 39: 41-46. 2017/12/13. DOI: 10.1007/s10792-017-0782-1 10.1007/s10792-017-0782-1 [pii].

10. Jin SW and Lee SM. Comparison of longitudinal changes in circumpapillary retinal nerve fiber layer and ganglion cell complex thickness after acute primary angle closure: a 12-month prospective study. Jpn J Ophthalmol 2018; 62: 194-200. 2017/12/23. DOI: 10.1007/s10384-017-0557-2 10.1007/s10384-017-0557-2 [pii].

11. Wang $X$, Jiang $C$, Kong $X$, et al. Peripapillary retinal vessel density in eyes with acute primary angle closure: an optical coherence tomography angiography study. Graefes Arch Clin Exp Ophthalmol 2017; 255: 1013-1018. 2017/02/06. DOI: 10.1007/s00417-017-3593-1 10.1007/s00417-017-3593-1 [pii].

12. Biermann J, van Oterendorp C, Stoykow C, et al. Evaluation of intraocular pressure elevation in a modified laser-induced glaucoma rat model. Exp Eye Res 2012; 104: 7-14. 2012/09/18. DOI: S00144835(12)00269-2 [pii] 10.1016/j.exer.2012.08.011.

13. Yadgarov A, Liu D, Crane ES, et al. Surgical Outcomes of Ahmed or Baerveldt Tube Shunt Implantation for medically Uncontrolled Traumatic Glaucoma. J Curr Glaucoma Pract 2017; 11: 16-21. 
2017/02/01. DOI: 10.5005/jp-journals-10008-1215.

14. Liu X, Yu FF, Zhong YM, et al. [The efficacy of Ahmed glaucoma valve implantation in the management of early stage of glaucoma secondary to blunt ocular trauma]. Zhonghua Yan Ke Za Zhi 2012; 48: 492-496. 2012/09/05.

15. Al-Jazzaf AM, Netland PA and Charles S. Incidence and management of elevated intraocular pressure after silicone oil injection. J Glaucoma 2005; 14: 40-46. 2005/01/15. DOI: 00061198200502000-00008 [pii].

16. Manna A, Foster P, Papadopoulos M, et al. Cyclodiode laser in the treatment of acute angle closure. Eye (Lond) 2012; 26: 742-745. 2012/02/04. DOI: eye2011361 [pii] 10.1038/eye.2011.361.

17. Chiam PJ and Sung VCT. The outcome of transscleral cyclophotocoagulation for the management of acute angle closure. Eur J Ophthalmo/ 2018; 28: 188-192. 2017/09/09. DOI: AB152E8AB9F4-45D6-B0EC-FE6D515CD6E9 [pii] 10.5301/ejo.5001026.

18. Fiess A, Shah P, Sii F, et al. Trabeculectomy or Transscleral Cyclophotocoagulation as Initial Treatment of Secondary Childhood Glaucoma in Northern Tanzania. J Glaucoma 2017; 26: 657-660. 2017/04/28. DOI: 10.1097/IJG.0000000000000682.

19. Rasmuson E, Linden C, Lundberg B, et al. Efficacy and safety of transscleral cyclophotocoagulation in Swedish glaucoma patients. Acta Ophthalmol 2019 2019/04/27. DOI: 10.1111/aos.14125.

20. Ghosh S, Manvikar S, Ray-Chaudhuri N, et al. Efficacy of transscleral diode laser cyclophotocoagulation in patients with good visual acuity. Eur J Ophthalmol 2014; 24: 375-381. 2013/11/19. DOI: 4436D81D-F4D5-4553-920E-7BF0FCD41902 [pii] 10.5301/ejo.5000389.

21. Shah P, Bhakta A, Vanner EA, et al. Safety and Efficacy of Diode Laser Transscleral Cyclophotocoagulation in Eyes With Good Visual Acuity. J Glaucoma 2018; 27: 874-879. 2018/08/17. DOI: $10.1097 /$ IJG.0000000000001057.

22. Ndulue JK, Rahmatnejad K, Sanvicente C, et al. Evolution of Cyclophotocoagulation. J Ophthalmic Vis Res 2018; 13: 55-61. 2018/02/07. DOI: 10.4103/jovr.jovr_190_17 JOVR-13-55 [pii].

23. De Gregorio A, Pedrotti E, Stevan G, et al. Safety and efficacy of multiple cyclocoagulation of ciliary bodies by high-intensity focused ultrasound in patients with glaucoma. Graefes Arch Clin Exp Ophthalmol2017; 255: 2429-2435. 2017/10/19. DOI: 10.1007/s00417-017-3817-4

10.1007/s00417-017-3817-4 [pii].

24. Williams AL, Moster MR, Rahmatnejad K, et al. Clinical Efficacy and Safety Profile of Micropulse Transscleral Cyclophotocoagulation in Refractory Glaucoma. J Glaucoma 2018; 27: 445-449. 
2018/03/10. DOI: 10.1097/IJG.0000000000000934.

25. Dastiridou Al, Katsanos A, Denis P, et al. Cyclodestructive Procedures in Glaucoma: A Review of Current and Emerging Options. Adv Ther 2018; 35: 2103-2127. 2018/11/19. DOI: 10.1007/s12325-0180837-3 10.1007/s12325-018-0837-3 [pii].

\section{Figures}

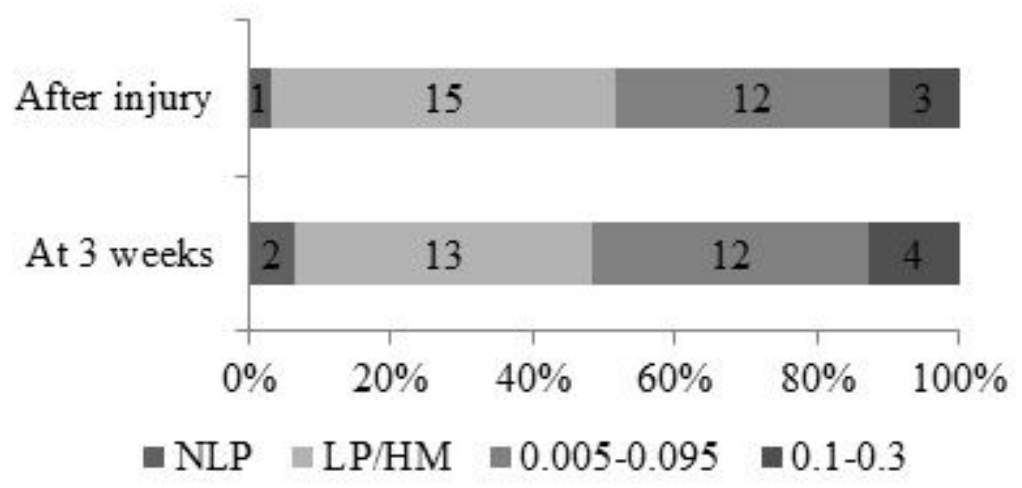

\section{Figure 1}

Constituent ratio of BCVA after injury and 3 weeks after treatment. The number of the injured eyes in each group was shown in the bar. 